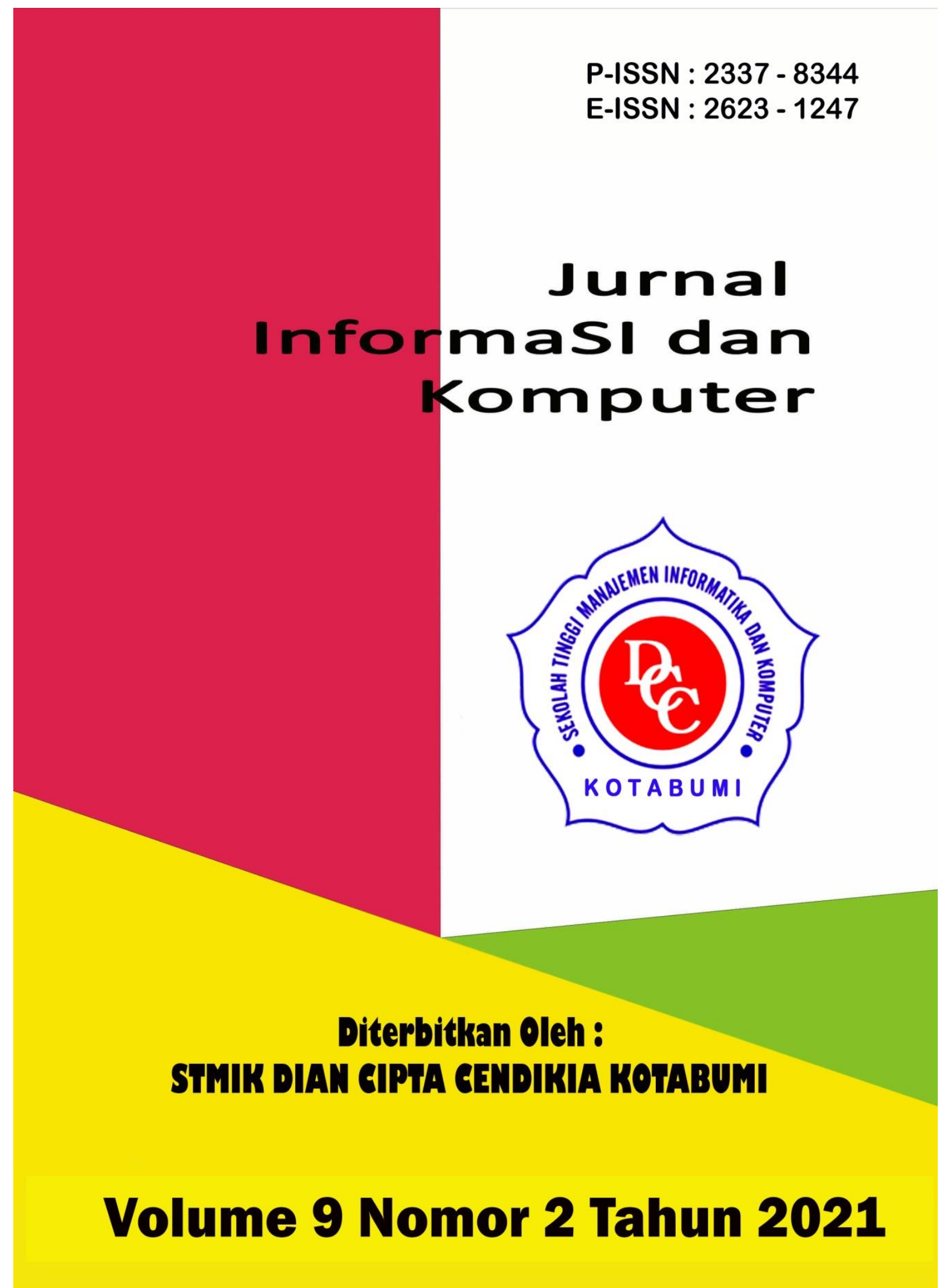




\section{Penerbit}

\section{Lembaga Penelitian STMIK Dian Cipta Cendikia Kotabumi}

Hak atas naskahh/tulisan tetap berada pada penulis, isi diluar tangung jawab penerbit dan Dewan Penyunting 


\section{PENGANTAR REDAKSI}

Puji syukur dipanjatkan kehadirat Tuhan Yang Maha Esa, atas karunia dan limpahan rahmatNYA jualah Jurnal Informasi dan komputer (JIK) STMIK Dian Cipta Cendikia Kotabumi ini dapat terwujud.Jurnal Informasi dan Komputer (JIK) yang terbit dua (2) kali dalam setahun ini merupakan suatu wadah untuk penyebar luasan hasil-hasil penelitian, studi pustaka, karya ilmiah yang berkaitan dengan Informasi dan Komputer khususnya bagi dosen-dosen STMIK Dian Cipta Cendikia Kotabumi serta umumnya para cendikiawan, praktisi, peneliti ilmu Informatika dan Komputer.

Harapan, dengan diterbitkannya Jurnal Informasi dan Komputer (JIK) ini sebagai salah satu bentuk sumbangan pemikiran dalam pengembangan ilmu informatika dan komputer yang berkaitan dengan kajian-kajian di bidang tekhnologi Informatik, Komunikasi Data dan Jaringan Komputer, perancangan dan Rekayasa Perangkat Lunak, serta ilmu-ilmu yang terkait dengan bidang Informasi dan Komputer lainnya.

Berkenaan dengan harapan tersebut, kepada para peneliti, dosen dan praktisi yang memiliki hasil-hasil penelitian, kajian pustaka, karya ilmiah dalam bidang tersebut diatas, dengan bangga redaksi Jurnal Informasi dan Komputer (JIK) menerima naskah ringkasan untuk dimuat pada jurnal Informasi dan Komputer (JIK) STMIK Dian Cipta Cendikia Kotabumi dengan berpedoman pada penulisan naskah jurnal sebagaimana dilampirkan pada halaman belakang (Bagian kulit dalam) buku jurnal ini.

Mutu dari suatu jurnal ilmiah tidak hanya ditentukan oleh para pengelolanya saja, tetapi para penulis dan pembaca jualah yang mempunyai peranan besar dalam meningkatkan mutu jurnal Informatika dan Komputer ini. Merujuk pada realita ini kamu sangat mengharapkan peran aktif dari peneliti untuk bersama-sama menjaga dan memelihara keberlangsungan dari jurnal Informasi dan Komputer STMIK Dian Cipta Cendikia Kotabumi ini. Yang juga tidak kalah pentingnya dari partisipasi tersebut diatas, adalah saran dan kritik yang membangun dari pembaca yang budiman agar kiranya dapat disampaikan langsung kepada redaksi JIK. Saran dan kritik yang membangun akan dijadikan masukan dan pertimbangan yang sangat berarti guna peningkatan mutu dan kualitas Jurnal Informasi dan Komputer STMIK Dian Cipta Cendikia Kotabumi.

Tak lupa diucapkan terima kasih yang tak terhingga atas perhatian dan kerjasama dari semua pihak yang tak dapat disebutkan satu persatu hingga dapat diterbitkan nya Jurnal Informasi dan Komputer (JIK) STMIK Dian Cipta Cendikia Kotabumi. Semoga apa yang telah diperbuat untuk kebaikan akan menjadi amal ibadah, amin.

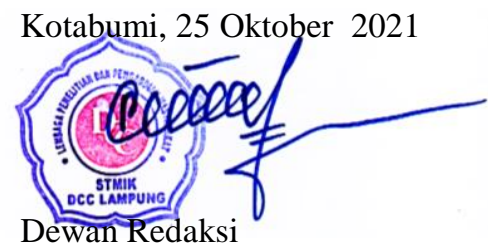




\section{JURNAL INFORMASI DAN KOMPUTER}

Volume 9 Nomor 2 Oktober 2021

Jurnal Informasi dan Komputer merupakan Sarana informasi ilmu pengetahuan, Tekhnologi dan Komunikasi yang berupa hasil penelitian, tulisan ilmiah, Ataupun studi pustaka. Jurnal ini terbit dua kali setahun pada bulan April dan Oktober. Berisi hasil penelitian ilmiah di bidang informatika yang bertujuan untuk menghubungkan adanya kesenjangan antar kemajuan teknologi dan hasil penelitian. Jurnal ini di terbitkan pertama kali pada tahun 2013.

Penanggung Jawab:

Ketua STMIK Dian Cipta Cendikia Kotabumi

\section{Pembina:}

Ketua STMIK Dian Cipta Cendikia Kotabumi Ketua Lembaga Penelitian STMIK Dian Cipta Cendikia Kotabumi

\section{Pimpinan Redaksi}

Dwi Marisa Efendi,.S.Kom.,M.Ti

\section{Redaksi pelaksana}

Rustam,.S.Kom,.M.Ti (STMIK Dian Cipta Cendikia Kotabumi)

Nurmayanti M.Kom (STMIK Dian Cipta Cendikia Kotabumi)

Sukatmi,.S.Kom., M.Kom (AMIK DCC Bandar Lampung)

Sampurna Dadi Riskiono,M.Kom (Universitas Teknokrat Indonesia)

Ifo Wahyu Pratama,S.Kom.,M.Ti(AMIK MASTER Lampung)

\section{Mitra Bestari}

Dr. RZ. ABDUL AZIZ, ST., MT (Institut Informatika dan Bisnis Darmajaya)

Dr. Dadang Sudrajat, S.Si, M.Kom (STMIK IKMI Cirebon)

Dr. Septafiansyah Dwi Putra, S.T., M.T (Politeknik Negeri Lampung)

Dr. Evi Grativiani, S.E., M.S.I (Universitas Sebelas Maret)

Rohmat Indra Borman ( Universitas Teknokrat Indonesia )

Ferry Wongso, S.KOm., M.Kom ( STMIK Darma Pala Riau)

Ferly Ardhy, S.Kom., M.Ti ( Universitas Aisyah Pringsewu )

Firmansyah, S.E., M.Si (STMIK Darma Pala Riau)
Amarudin (Universitas Teknokrat Indonesia)

Didi Susianto, S.T., M.Kom (AMIK Dian Cipta Cendika Bandar Lampung)

Alhibarsyah, St., M.Kom (STMIK Tunas

Bangsa Bandar Lampung)

Kemal Farouq Mauladi, S.Kom .M.Kom (Universitas Islam Lamongan)

Rima Mawarni, M.Kom ( STMIK Dian Cipta Cendikia Kotabumi)

Wira Jaya Hartono, S.Pd., M.Pd ( STMIK Darma Pala Riau)

Penerbit : STMIK Dian Cipta Cendikia Kotabumi Bekerja Sama Dengan LPPM STMIK Dian Cipta Cendikia Kotabumi.

\section{Alamat Redaksi/Penerbit:}

Jl. Negara No. 3 Candimas Kotabumi Lampung Utara

No Telpon/Fax 072423003

Email : 1ppm-stmik@dcc.ac.id 




\section{JURNAL INFORMASI DAN KOMPUTER VOL. 9 NO. 2 THN. 2021}

\section{DAFTAR ISI}

Halaman

Sistem Informasi Akuntansi Persedian Barang Berbasis Web Pada Lembaga

Permasyarakatan Kelas II A Banceuy Bandung : "Kelompok Tani Desa Banjar Kertarahayu" Teuku Rian Hardiyansyah, Fatia Salsa Azzahra (Politeknik Piksi Ganesha Bandung ${ }^{1,2}$ )

Penerapan Finite State Automata Pada Vending Machine Penjual Obat Non Resep

Dokter Dan Keperluan Medis

Eko Supriyanto $^{1}$, Angga Ardiansyah ${ }^{2}$, Frieyadie $^{3}$, Sri Rahayu ${ }^{4}$, Windu Gata ${ }^{5}$

(Universitas Nusa Mandiri ${ }^{12}$ )

Sistem Pendukung Keputusan Untuk Menentukan Kelayakan Pengajuan Sertifikasi Guru Dengan Metode Simple Additive Weighting (Studi Kasus : Ma Al Muhajirin Janti Jogoroto Jombang)

Budiman, umam baharudin, winarti

(Universitas Darul 'Ulum Jombang)

Perancangan Infrastruktur Domain Name Server Lokal Menggunakan Ubuntu Server 16.04

Pada PT. Xyz

Zaenal Mutaqin Subekti, Hendra Setiawan, Satria, Widia Murni Wijaya,

Aliy Hafiz, Warsudi

(STMIK Bani Saleh, Universitas Negeri Yogyakarta, AMIK Dian Cipta Cendikia,

STMIK MIC CIkarang)

Perancangan Sistem Informasi Idea Proposal (Ip) Berbasis Web Pada Pt. Paxel Algorita Unggul

Julian Murhan Sahputra, Indah Purnamasari

(Universitas Nusa Mandiri ${ }^{12}$ )

Sistem Pendukung Keputusan Untuk Menentukan Ekstrakurikuler Atletik

Berdasarkan Bakat Siswa Menggunakan Metode Profile Matching

Agnes Basuki, Petrus Sokibi, Tiara Eka Putri

(Universitas Catur Insan Cendekia)

Penerapan Algoritma K-Means Untuk Pengelompokan Usia Calon Penerima Vaksin

Di Kab. Ngawi

Irna Yuniarfi, Saifulloh

(Universitas PGRI Madiun ${ }^{12}$ )

System Penilaian Seleksi Calon Karyawan Baru Menggunakan Metode Simple Additive Weighting (SAW) Di PT.TNA

Anik Sri Wahyuningsih, Yudhi Firmansyah

(Universitas Panca Sakti Bekasi ) 
Perancangan Sistem Informasi Pembayaran SPP Menggunakan Framework Laravel Ichwan Habib Moudi

(Universitas Panca Sakti Bekasi)

Implementasi Algoritma K-Means Dan Algoritma Apriori Optimasi Kinerja Ecu

(Study Kasus Mobil Avanza Dan Xenia)

Sigit Mintoro' Asep Afandi

(STMIK Dian Cipta Cendikia Kotabumi)

Sistem Pakar Penyakit Buah Kakao Untuk Peningkatan Hasil Panen Kakao Menggunakan

Metode Case Base Reasoning (CBR) Berbasis Web Mobile

Aliy hafiz, Verawati

(AMIK Dian Cipta Cendikia,Bandar Lampung)

Penerapan Metode Rapid Application Develomment (RAD) Dalam Pengembangan

Sistem Pemesanan Menu Berbasis Android

Aris Baihaqi, Tumini

(Fakultas Sains dan Teknologi ${ }^{1,2}$ )

Rancang Bangun Sistem Informasi Geografis Pariwisata Di Lampung Timur

Sukatmi, Rexa Alfa Rizi

(AMIK DCC Bandar Lampung ${ }^{12}$ )

Implementasi Psak No. 45 Pada Proses Penyusunan Laporan Keuangan Menggunakan

M.S. Excel Dan Aplikasi Accurate Accouting Pada STMIK Bani Saleh

Marhakim, Willy Adam

(STMIK Bani Saleh ${ }^{12}$ )

Sistem Prediksi Harga KOPI LAMBAR ( Lampung Barat) Dengan Metode

Backpropagation, dan Double Exponential ( Studi Kasus BUMDES )

Supriyanto, Dwi marisa Efendi,Rhomadhon

(STMIK Dian Cipta cendikia Kotabumi ${ }^{1-}$ )

Sistem Informasi Pemasaran Produk Umkm Berbasis Web Pada Kecamatan Bumi

Nabung Lampung Tengah

Yuli Syafitri, Agus Prasetyo, Reni Astika

(AMIK Dian Cipta Cendikia Bandar Lampung)

Rancang Bangun Aplikasi Pembelajaran Aksara Lampung Berbasis Android

Ferly Ardhy, Hendra Syahrobi

(Universitas Aisyah Pringewu ${ }^{1,}$ STMIK Dian Cipta Cendikia ${ }^{2}$ )

Sistem Pakar Diagnosa Penyakit Kulit Pada Balita Menggunakan Metode Naïve

Bayes Dan Forward Chaining Studi Kasus Puskesmas Cempaka Sungkai Selatan

Sidik Rahmatullah, Rima Mawarni

(STMIK Dian Cipta Cendikia Kotabumi ${ }^{12}$ )

Rekayasa Perangkat Lunak Perhitungan Harga Pokok Produksi Metode

Full Costing Pada Umkm Mitra Cake Di Bandar Lampung

Pitrawati, Arif Sanjaya

(AMIK Dian Cipta Cendikia, Bandar Lampung) 
Rancang Bangun Sistem Ujian Online Menggunakan Algoritma Cosine Similarity

Berbasis Web

Haryono, Zaenal Mutaqin Subekti, Widiyawati, Hidayatullah

(STMIK Bani Saleh ${ }^{1234}$ )

Model Aplikasi Helpdesk Ticketing System Berbasis Web Menggunakan Metode Rad

Indra Permana

Pattern Recognition Tulisan Tangan Huruf Hijaiyah Menggunakan Metode

Convolutional Neural Network (CNN)

Mufassiril Abror, Nopiyanto

(Universitas Panca Sakti Bekasi ${ }^{12}$ )

Aplikasi Sistem Informasi Keuangan Berbasis Android Di Perumahan Taman

Karang Bahagia

Melda Ayulestari

(Universitas Panca Sakti Bekasi)

Audit Pelayanan Sistem Rujukan Online Puskesmas Menggunakan Framework COBIT 5.0

Nurmayanti, Merri Parida, Ngajiyanto, Ina Anzalna

(STMIK Dian Cipta Cendikia Kotabumi ${ }^{1234}$ )

Perancangan Sistem Informasi Pengolahan Data Nilai Siswa Berbasis Web

Erin Ermawati, Anik Sri Wahyuningsih

(Fakultas Sain dan Teknologi, Universitas Panca Sakti Bekasi ${ }^{12}$ )

Pengembangan Sistem Pelaporan Data Hasil Inspeksi Barang Berbasis Web

Siska Putriani

(Universitas Pancasakti Bekasi)

Penerapan Extreme Programming Dalam Perancangan Aplikasi Web Food Market

Tumini, Hilman Septiana

(Fakultas Sains dan Teknologi Universitas Panca Sakti Bekasi ${ }^{1,2}$ )

Sistem Pencarian Barang Berbasis Website Menggunakan Php Dan Mysq1

Studi Kasus PT. Surya Technology Industri Sulaeman

(Universitas Panca Sakti Bekasi)

Implementasi Metode Prototype Pada Sistem Peminjaman Alat Kerja Berbasis Web

Di PT SK Metalindo

Ali Mulyanto, Arjun Gunawan

(Univeritas Panca Sakti Bekasi)

Aplikasi Tata Cara Wudhu Menggunakan Teknologi Augmented Reality

Sebagai Media Pembelajaran Di TK Al Fatih

Ahmad Yakub, Idarul Fadli

(Universitas Panca Sakti Bekasi ${ }^{12}$ )

Sistem Pakar Diagnosa Penyakit Ayam Petelur Menggunakan Metode Certainty Factor

Berbasis Web Mochammad

Taufiq Hidayat, Ali Mulyanto

(Universitas Panca Sakti Bekasi ${ }^{12}$ ) 
Penerapan Metode Prototyping Dalam Perhitungan Hasil Produksi Menggunakan

Arduino Uno R3 Dan Php Di PT. Indonesia Epson Industry

Amandha Aulia, Ajar Rohmanu

(Universitas Panca Sakti Bekasi ${ }^{12}$ )

System Pendukung Keputusan Penentuan Guru Teladan Dengan Metode Profile Matching

Hasbulloh, Agmawarnida

(Universitas Panca Sakti Bekasi ${ }^{1,2}$ )

Implementasi Waterfall Method Pada Aplikasi Buku Induk Siswa Berbasis Web

Idam Holid, Yogie Krisnayadi

(Universitas Panca Sakti ${ }^{12}$ )

Pengembangan Text To Speech Media Pembelajaran Untuk Pengenalan

Anggota Tubuh Manusia Kelas V Sekolah Dasar

Juwanda Saputra, Ali Mulianto

(Teknik Infomratika Fakulutas Sains dan Teknologi ${ }^{12}$ )

Perancangan Sistem Peminjaman Barang Berupa Aset Tetap Berbasis Web

Pada Lembaga Permasyarakatan Kelas II A Banceuy Bandung

Guntur Salasa Priambodo, Perwito, Candra Mecca Sufyana

(Politeknik Piksi Ganesha Bandung ${ }^{1,2,3}$ )

Metode Pemilihan Karyawan Terbaik Sebagai Penentu Goodwill Perguruan Tinggi

Dengan Menggunakan Metode Topsis (Studi Kasus Perguruan Tinggi Di Lampung Utara)

Dwi Sartika, Pakarti Riswanto

(STMIK Dian Cipta Cendikia Kotabumi)

Sistem Pendukung Keputusan Pemilihan Merek Smartphone Menggunakan

Metode Analytical Hierarchy Process (AHP)

Ade Kiki Fatmawati, Muhammad Sultan Raflie, Norma Yunita

(Universitas Nusa Mandiri ${ }^{123}$ )

Pattern Recognition Aksara Lampung Menggunakan Algoritma Neural Network

Metode Analytical Hierarchy Process (AHP)

Nopiyanto, Rahmadi

(Universitas Panca Sakti Bekasi) 


\title{
PERANCANGAN SISTEM INFORMASI PEMBAYARAN SPP MENGGUNAKAN FRAMEWORK LARAVEL
}

\author{
Ichwan Habib Moudi \\ Universitas Panca Sakti Bekasi \\ J1. Kapten Sumantri No 16 Cikarang 17530 Jawa Barat, Indonesia \\ E-mail : ichwanhabibmoudi@gmail.com
}

\begin{abstract}
ABSTRAK
Perkembangan Teknologi dan ilmu pengetahuan sangat begitu pesat dengan didukungnya sumber daya manusia yang berkualitas dan memadai, tidak terkecuali perkembangan di bidang pendidikan yang dapat membantu sekolah terutama dalam mengolah data pembayaran sekolah, dengan demikian untuk membuat Sistem Informasi Pembayaran SPP yang dapat membantu proses pengolahan data administrasi pembayaran sekolah. Sistem informasi pembayaran SPP sekolah dibuat dengan menggunakan bahasa pemrograman Laravel serta menggunakan database MySQL dan menggunakan metode SDLC. Sistem informasi pembayaran SPP yang penggunaanya untuk bendahara, admin dan super admin. Diharapkan dengan adanya sistem ini hasil yang didapat menjadi lebih baik untuk sekolah dan bisa memaksimalkan kinerja petugas dalam melakukan pembayaran iuran siswa serta informasi yang didapat lebih efektif dan efesien.
\end{abstract}

Kata kunci : Sistem Informasi, Pembayaran SPP, Laravel, MySQL, metode SDLC.

\section{ABSTRACTS}

The development of technology and science is very rapid with the support of qualified and adequate human resources, no exception developments in the field of education that can help schools, especially in processing school payment data, thus to create an SPP Payment Information System that can assist the processing of school payment administration data. The school tuition payment information system is made using the Laravel programming language and uses a MySQL database and uses the SDLC method. SPP payment information system that is used for treasurers, admins and super admin. It is hoped that with this system the results obtained will be better for schools and can maximize the performance of officers in making student payments and the information obtained is more effective and efficient.

Keywords: Information System, SPP Payment, Laravel, MySQL, SDLC method

\section{PENDAHULUAN}

Teknologi komputer digunakan untuk menunjang kualitas suatu pendidikan, mulai dari proses kegiatan pembelajaran hingga proses pengolahan data manajemen sekolah dan dalam upaya peningkatan mutu sumber daya manusia (SDM) serta proses kelancaran dari administrasi sekolah khususnya sistem pembayaran SPP (Sumbangan Penyelenggaraan Pendidikan) yang membutuhkan kecepatan dan ketepatan agar pelayanan terhadap masyarakat khususnya wali siswa dan siswa itu sendiri dapat dilayani dengan profesional. Beberapa permasalahan yang sering muncul adalah pelayanan pembayaran SPP. Pencatatan yang masih manual menyebabkan terkadang terjadinya human error, karena pencatatan terkadang dilakukan seadanya.

Dengan demikian, adanya sistem pembayaran SPP yang dirancang ini dapat diterapkan dengan baik dan membantu untuk mengurangi permasalahan yang tengah dihadapi oleh sekolah. berdasarkan permikiran tersebut di atas maka dibangun sebuah sistem yang diharapkan mampu membantu pihak Sekolah dalam kelancaran proses pembayaran SPP siswa dengan cepat serta pelaporan keuangan, dengan membuat Perancangan Sistem 
Informasi Pembayaran SPP Menggunakan Framework Laravel.

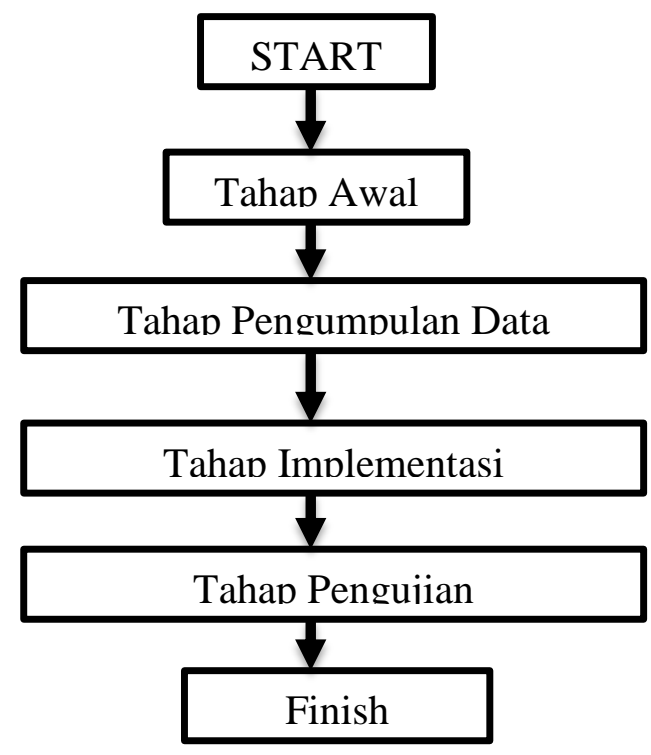

Gambar 1. Alur Penelitian

\section{METODE PENELITIAN}

Tahapan Penelitian untuk pembayaran SPP, menggunakan metode pengembangan perangkat lunak SDLC (System Development Life Cycle)[2] . Metode SDLC adalah tahaptahap pengembangan sistem informasi yang pertama kali dikembangkan yang dilakukan oleh analisis sistem dan programmer untuk membangun sebuah sistem informasi. Metode SDLC ini seringkali dinamakan sebagai proses pemecahan masalah, yang langkah-langkahnya adalah :

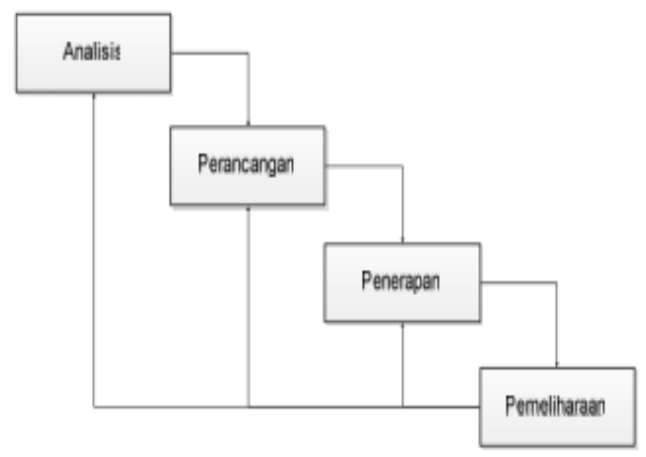

\subsection{Analisis}

Merupakan tahap dimana cara ini digunakan untuk mentukan judul penelitian, mencari objek, serta mencari referensi untuk bahan penelitian ini.

\subsection{Perancangan}

Tahapan ini menjelaskan bagaimana menterjemahkan keinginan pemakai sistem informasi tersebut kedalam bahasa komputer, untuk memulai merancang suatu sistem informasi baru yang meliputi : input, file-file database dan output, bahasa yang digunakan, metode dan prosedur serta pengendalian

\subsection{Penerapan}

Hasil penyusunan sistem informasi adalah sebuah software computer yang siap digunakan untuk kebutuhan user untuk dioperasikan

\subsection{Pemeliharaan}

Pemeliharaan yang dilakukan analis adalah dengan melakukan perbaikan dan pemeliharaan pada kesalahan atau kegagalan yang timbul dalam penggunaan sistem informasi.

\section{HASIL DAN PEMBAHASAN}

Berdasarkan Hasil Analisis, sistem yang digunakan pada SMK TON'S masih menggunakan sistem manual, hal ini membutuhkan waktu yang cukup lama dan kurang efisien. Dalam proses pelaporan yang merupakan bagian penting juga dikerjakan dengan sistem manual, sehingga mungkinan terjadinya kesalahan. Selain itu juga membutuhkan waktu yang lama dalam proses pengejaannya dan juga dapat mempengaruhi proses pengambilan keputusan.

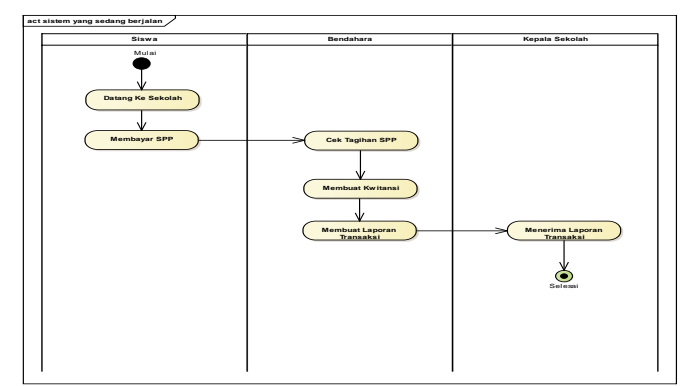

Gambar 3. Sistem yang sedang berjalan 3.1 Analisis Sistem yang diusulkan 
Dari data analisa sistem yang lama maka dapat di analisakan kembali kebutuhan sistem yang baru sebagai berikut :

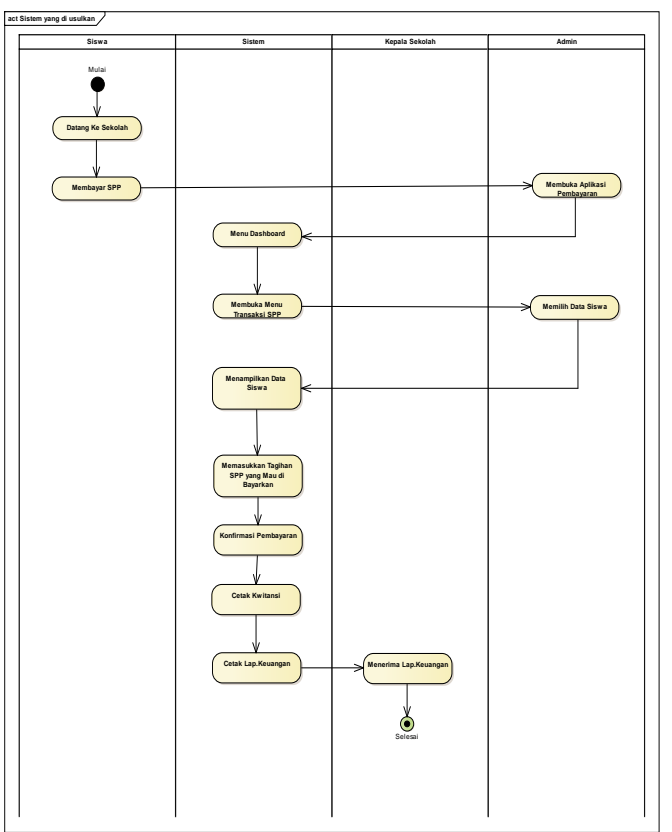

Gambar 4. Sistemyang diusulkan

Kebutuhan Fungsional Sistem dapat menyediakan Login untuk Petugas yaitu Admin yang mempunyai hak akses

Tabel 1. Kebutuhan Sistem Baru

\begin{tabular}{|c|l|}
\hline NO & \multicolumn{1}{|c|}{ KEBUTUHAN SISTEM BARU } \\
\hline 1 & $\begin{array}{l}\text { Dapat melihat seluruh data yang ada di } \\
\text { aplikasi. }\end{array}$ \\
\hline 2 & $\begin{array}{l}\text { Petugas dapat edit semua data dan } \\
\text { melakukan transaksi ke dalam aplikasi. }\end{array}$ \\
\hline 3 & $\begin{array}{l}\text { Sistem dapat memberikan informasi } \\
\text { laporan pembayaran. }\end{array}$ \\
\hline
\end{tabular}

\subsection{Perancangan Sistem}

Dalam Tahap ini hasil dari analisa kebutuhan yang telah dibuat digambarkan kesebuah perancangan.Desain ini menggambarkan sistem yang dibuat sehingga pengguna dapat memperoleh gambaran dari sistem.

\section{A. Use Case Diagram}

Use case diagram dapat dikatakan adalah sebuah abstraksi hubungan antara system dengan aktor yang menggunakan sistem itu sendiri. Use case bekerja dengan menjalankan tipe interaksi antara user dengan sebuah sistem tentang bagaimana sistem tersebut dipakai.[3]

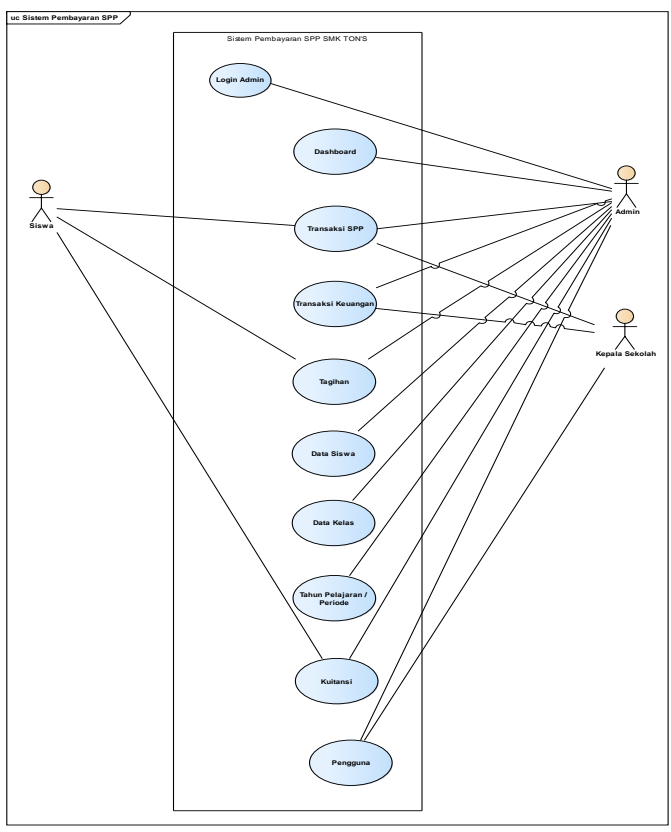

Gambar 5. Diagram Use Case Sistem Pembayaran SPP

\section{B. Class Diagram}

Tujuan utama dari diagram kelas adalah untuk menciptakan sebuah kosa kata yang digunakan untuk menuangkan pemikiran analys agar dapat diterima oleh pengguna.[3]

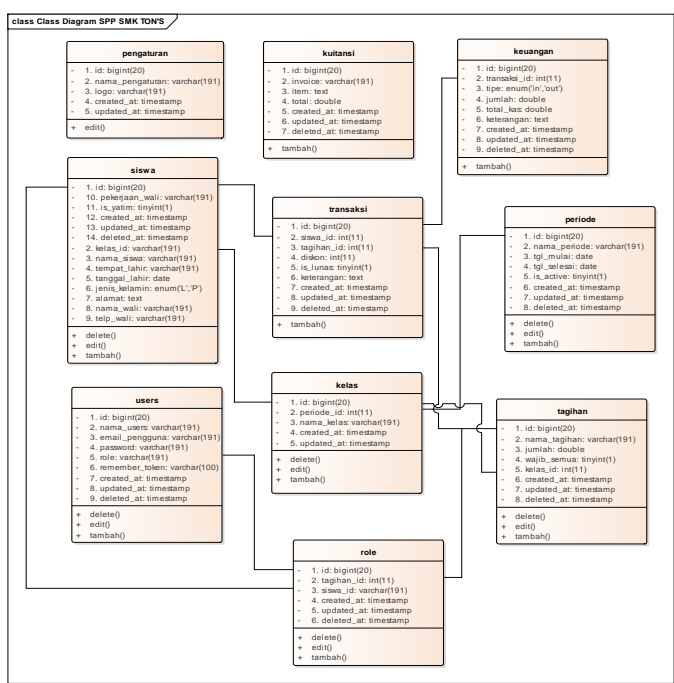

Gambar 6. Class Diagram Sistem Pembayaran SPP

\section{Activity Diagram}


Diagram aktifitas adalah sebuah diagram yang menggambarkan bagaimana alur suatu sistem yang dirancang itu berjalan.[3]

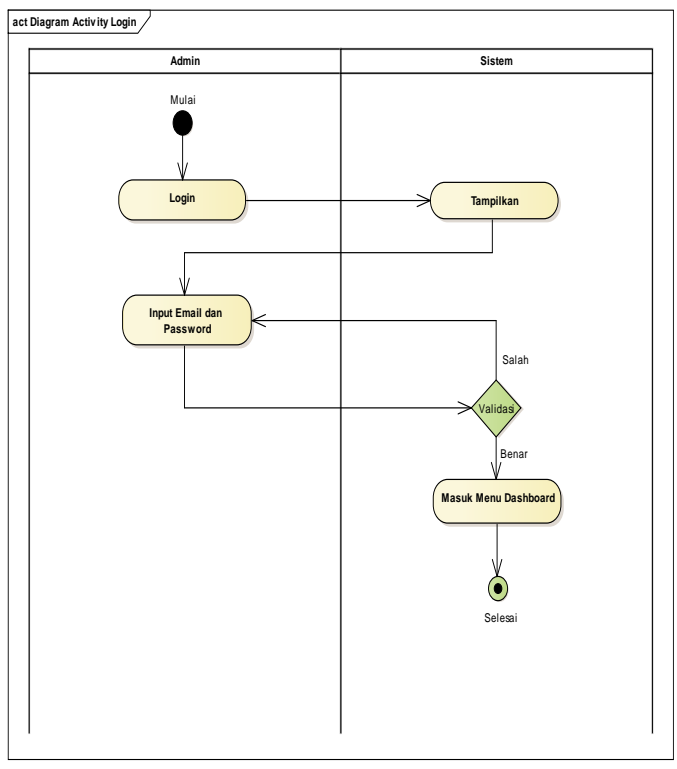

Gambar 7. Activity Diagram Login

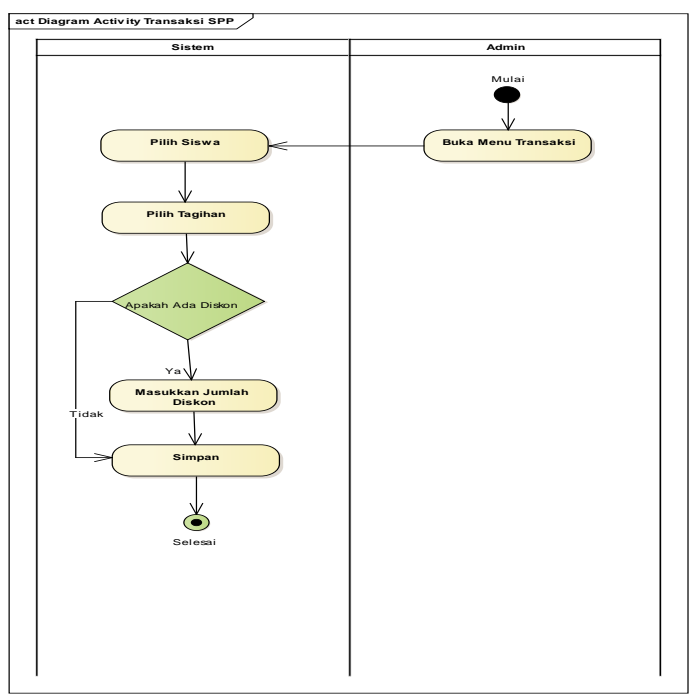

Gambar 8. Activity Diagram Transaksi SPP

\section{Sequance Diagram}

Squence Diagram atau bisa disebut sebagai diagram urutan adalah suatu diagram yang menggambarkan skenario program berjalan dimulai dari level yang paling rendah hingga sampai ke level yang paling tinggi dalam sebuah sistem secara berurutan.[3]

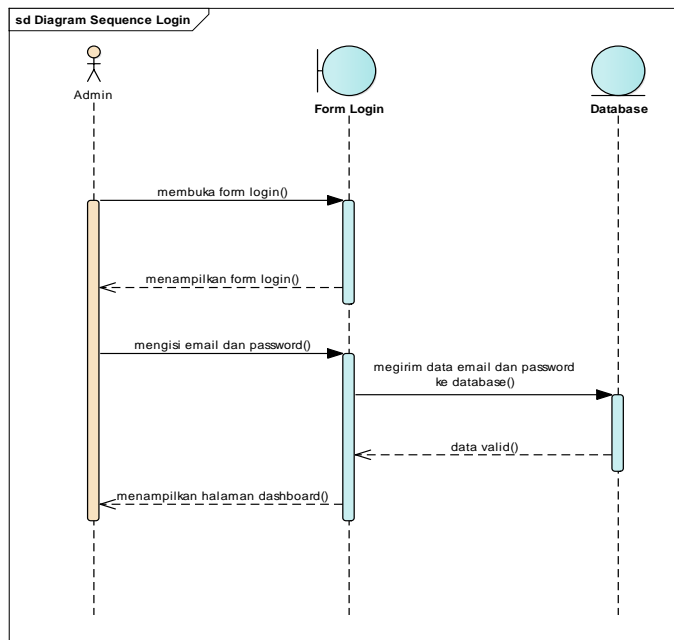

Gambar 9. Sequance Diagram Login

Untuk melakukan Login dimulai dari admin menjalankan sistem informasi, kemudian ke halaman Login. Sequence Diagram Login ditunjukan oleh gambar diatas

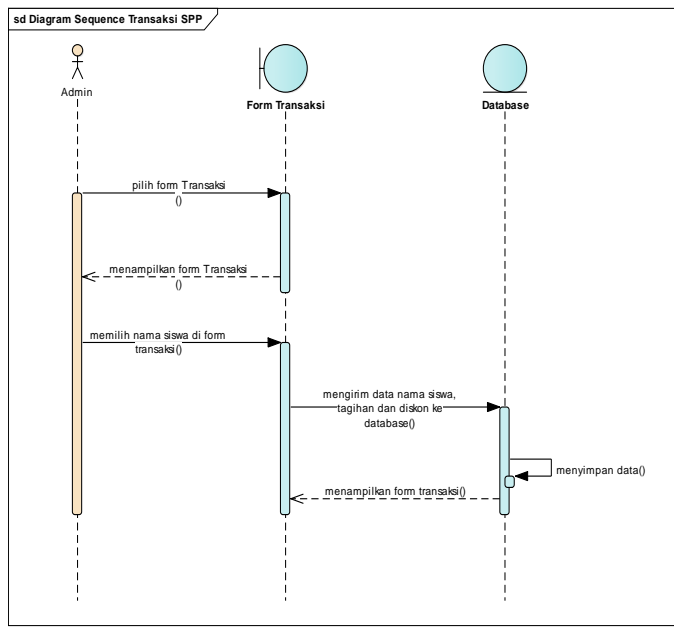

Gambar 10.Sequance Diagram Transaksi SPP

Untuk melakukan Transaksi SPP dimulai dari admin menjalankan sistem informasi, kemudian ke halaman Transaksi SPP. Sequence Diagram Transaksi SPP ditunjukan oleh gambar diatas.

\section{E. Perancangan Antarmuka}

Perancangan Desain antarmuka dilakukan untuk memberikan gambaran mengenai pengembangan sistem. Desain ini terdiri dari 
rancangan beberapa halaman yang dapat dilihat oleh pengguna. Hasil desain antarmuka

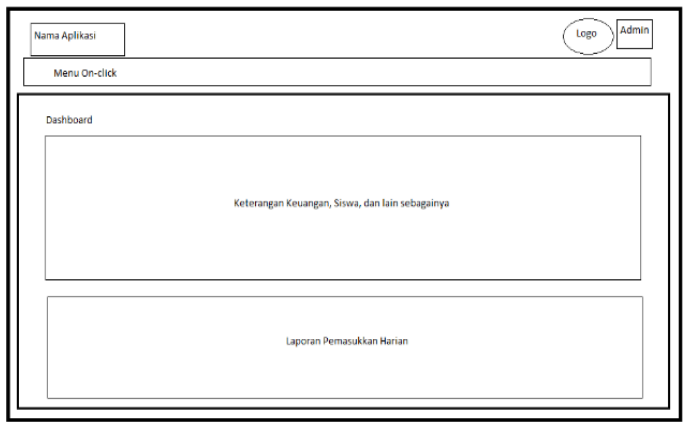

Gambar 11. Desain Antarmuka

\subsection{Penerapan Sistem}

Penerapan antarmuka (user interface) dilakukan menggunakan Laravel 7.0. Berikut hasil penerapan user interface Sistem Informasi Pembayaran SPP Berbasis Web.

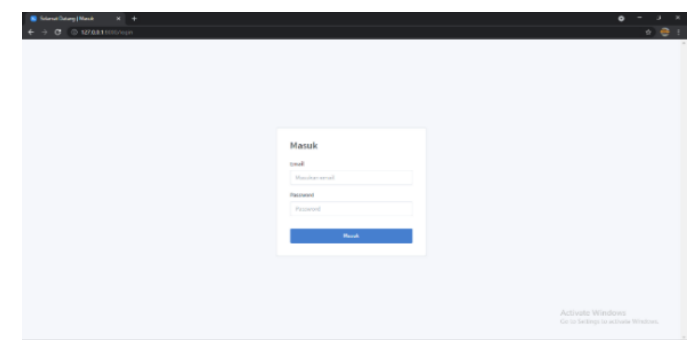

Gambar 12. Halaman Login

Gambar 11 di atas merupakan Tampilan Form Login untuk mengakses atau masuk pada halaman sistem informasi pembayaran SPP sesuai hak akses yang ditetapkan, hak akses itu meliputi Super Admin, Admin dan Bendahara.

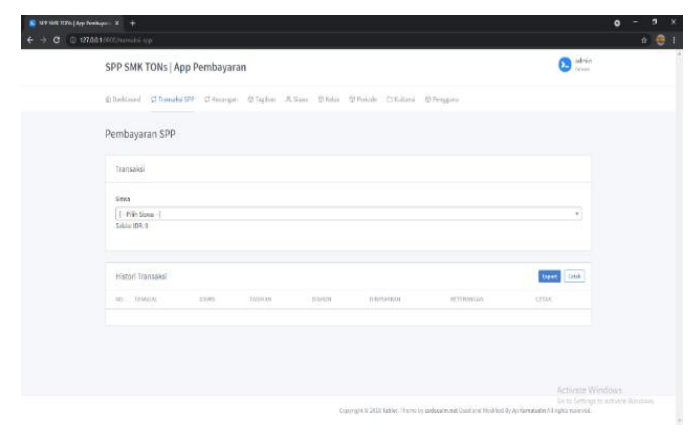

Gambar 13. Halaman Transaksi SPP (Before Running) terlampir pada gambar berikut.

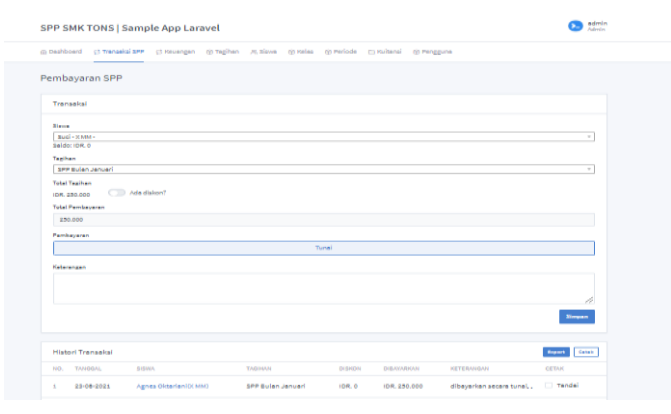

Gambar 14. Halaman Transaksi SPP (After Running)

Gambar 12. di atas merupakan Tampilan menu Transaksi SPP sesebelum melakukan sistem informasi pembayaran SPP (Default View) sedangkan Gambar 13. diatas merupakan Tampilan menu Transaksi SPP pada saat menjalankan sistem informasi pembayaran SPP.

\subsection{Pemeliharaan Sistem}

Pemeliharaan sistem digunakan untuk upaya memperbaiki, menjaga, mengulangi, dan mengembangkan sistem yang ada. Pemeliharaan ini juga diperlukan untuk meningkatkan efisiensi dan efektifitas kinerja sistem yang ada, supaya dalam penggunaannya tetap dalam keadaan optimal sesuai dengan yang diinginkan pengguna. Jenis pemeliharaan yang dimaksud adalah:

a. Melaksanakan pemantauan secara rutin minimal 3 bulan sekali

b. Melakukan backup data ke penyimpanan luar yang lain untuk menjaga data yang telah ada sebelumnya.

c. Melakukan perbaikan jika terjadi kesalahan atau kekurangan pada sistem.

\section{KESIMPULAN}

Berdasarkan hasil penelitian dan pembahasan dari tugas akhir maka penulis mengambil kesimpulan sebagai berikut :

a. Permasalahan terhadap sistem yang dijalankan pada saat ini di SMK TON'S yaitu masih menggunakan sistem secara manual, informasi data yang dihasilkan tidak efektif sehingga mudah terjadinya kehilangan data maupun terjadinya 
penggandaan dan redudansi data.

b. Dengan adanya sistem pembayaran SPP ini diharapkan agar dapat mempercepat SMK TON'S dalam penyimpanan data pembayaran SPP pada siswa agar lebih aman.

c. Dalam pembuatan sistem yang diusulkan yaitu aplikasi offline berbasis web dan menggunakan database dalam penyimpanan datanya.

d. Aplikasi ini dapat merekap laporan keuangan agar lebih efektif tiap bulannya tanpa mencatat nama siswa setiap ingin membayar SPP serta wali atau orang tua siswa tidak harus membawa kartu iuran setiap ingin membayar SPP.

Saran yang dapat diberikan oleh penulis untuk mengembangkan aplikasi pembayaran SPP ini adalah :

a. Sistem Informasi Pembayaran SPP tidak dapat diakses secara online, sehingga untuk penelitian berikutnya diharapkan dapat mengembangkan sistem ini supaya bisa digunakan secara online.

b. Sistem informasi pembayaran SPP yang sudah dibangun ini masih memiliki tampilan yang sederhana dari segi tampilan dan proses untuk itu masih perlu dikembangkan lagi dengan menambahkan aplikasi dan menambah tema menggunakan desain sehingga tampilan terlihat lebih menarik.

\section{DAFTAR PUSTAKA}

[1] Krismaji," Sistem Informasi Akuntansi edisi ketiga", 2015.

[2] Aji Raino Baswananda,"Sistem Pembayaran SPP Berbasis Komputer Pada SMAN Kesatriaan 1 emarang." Universitas Dian Nuswantoro Semarang. (2012)

[3] Sholiq. " Pemodelan Sistem Informasi
Berorientasi Obyek dengan UML.", 2006

[4] The Liang Gie. "Administrasi Perkantoran Modern.", 2000

[5] Rivai Sungkowo. " Prototipe Sistem Monitoring Control Pengembangan Aplikasi Pada Perguruan Tinggi Raharja.", Universitas Raharja. (2013)

[6] Merza Dheo Prakoso and Herlawati . "Sistem Informasi Pembayaran Biaya Pendidikan Siswa Pada SMK Perwira Bangsa Bekasi Utara.", Bina Insani Ict Journal (2017)

[7] Sulistiya Dwi Ningsih, Ani Oktarini Sari and Eva Zuraidah. "Implementasi Aplikasi Pembayaran Spp Pada Tk Al - Hidayah Tangerang." Jurnal PROSISKO (2021)

[8] Mellinda Ayu Mahanani. " Sistem Informasi Pembayaran SPP Berbasis Web Pada SMK Negeri 1 Bancak.", Universitas Kristen Satya Wacana. (2015)

[9] Hendrik Ika Dita Widia. " Sistem Informasi Pembayaran SPP Pada SMK Pawyatan Daha 3 Kediri.", Universitas Kristen Satya Wacana. (2017)

[10] Arislan Haikal Khalis. " Analisis Dan Pembuatan Sistem Informasi Pembayaran Administrasi Sekolah Pada Smkn 2 Klaten.", Universitas Amikom Yogyakarta.

(2017) 